\title{
Psychiatric Co-Morbidities of Suicide Attempters: A Cross Sectional Observation in a Tertiary Care Hospital of North India
}

\author{
Shaveta Bhagat ${ }^{1}$, Mohammad Maqbool Dar², Ibrar Ahmed ${ }^{3}$, Irm Yasmeen ${ }^{4}$, \\ Shazia Bashir ${ }^{5}$ \\ ${ }^{1}$ PG Student, Department of Psychiatry, Institute of Mental Health and Neurosciences-Kashmir Government \\ Medical College and Associated Hospitals, Srinagar \\ ${ }^{2}$ HOD, Department of Psychiatry, Institute of Mental Health and Neurosciences-Kashmir Government Medical \\ College and Associated Hospitals, Srinagar \\ ${ }^{3}$ PG Student, Department of Paediatrics, Government Medical College and Associated Hospitals, Srinagar. \\ ${ }^{4}$ Ex-SR Department of Blood Transfusion and Immunohaematology, Sher-e Kashmir Institute of Medical \\ Sciences, Soura, Srinagar \\ ${ }^{5}$ SR Department of Pathology, Government Medical College and Associated Hospital, Rajouri
}

Corresponding Author: Irm Yasmeen

\begin{abstract}
Background: Psychiatric disorders are at increased risk for suicide. Attempted suicide is a common clinical problem in a general hospital. It has a serious clinical and socio-economical impact too.
\end{abstract}

Aims: This study was carried out to assess the prevalence of psychiatric co-morbidities of suicide attempters attending the emergency.

Material and methods: This study was a cross sectional, observational study which was conducted at the Community General Hospital Unit, Institute of Mental Health and Neurosciences-Kashmir an associated hospital of Government Medical College Srinagar among the suicide patients attending the outpatient service and inpatient services of the hospital fulfilling inclusion and exclusion criteria over a period of one and a half year, from November 2017 to May 2019. Written informed consent was obtained in a simple and easily understandable unambiguous language. For the diagnosis of psychiatric comorbidity, we used MINI International Neuropsychiatric Interview Schedule Plus (MINI PLUS). A pvalue of $<0.05$ was taken as statistically significant.

Results: A total of 221 cases who had been admitted following unsuccessful suicide attempts to the emergency and psychiatry department were taken up for the study. They were evaluated in detail with regards to past attempt of suicide, family history of psychiatric illness or suicide and the presence of psychiatric co-morbidity and the results have been presented below in tabulated and graphical forms. $77.4 \%$ of the attempters had no history of psychiatric illness in their family while $22.6 \%$ of patients did have family history of a psychiatric illness. $98.2 \%$ of attempters had no family history of suicide while $1.8 \%$ of the patients gave a family history of suicide. $21.26 \%$ males and $54.75 \%$ females had associated psychiatric co-morbidities and $23.9 \%$ had no associated psychiatric co-morbidities.

Conclusion: The most common psychiatric morbidity associated with suicide was found to be major depressive disorder. Most importantly, the suicide attempters should be looked with sympathy rather than with a grimace on face. Such people should not be stigmatized and we should not let their shoulders drop.

Key Words: Depression, Bipolar Disorder, Morbidity, Suicide

\section{INTRODUCTION}

Suicide is an important and serious public health problem. The word suicide derived from Latin word for "self-murder", is a fatal act that represents the person's 
wish to die. ${ }^{1}$ The word suicide was first used by the English author, Sir Thomas Browne in 1642 in his treatise "Religio Medici". Suicide attempts represent a major risk factor for future suicide attempts and eventual completed suicide. ${ }^{2-4}$ In a community sample, a prior suicide attempt increased the chance of a future attempt 18 fold. ${ }^{5}$ Lecomte and Fornes ${ }^{6}$ found that onethird of youth who died by suicide had previously attempted suicide at least once. Adolescents with a history of more than one attempt may have increased risk for subsequent suicidality relative to adolescents with a single prior attempt, who in turn are at increased risk relative to adolescents with prior ideation but no attempt. Despite the apparent differences in risk, little work has been done to describe these distinct groups in terms of diagnostic differences, particularly among adolescents. $^{7,8}$

Considering the recent upward trend of suicides in Kashmir, this study aimed at looking at the different co-morbidities of this group of population and to demonstrate a temporal relationship between the act of suicide and a recent increase in the number of events that require a socially adaptive response on the part of individual. This study will go a long way in deciphering such precipitating factors and also in making future strategies for their management.

Aims: This study was conducted to assess the prevalence of psychiatric co-morbidities of suicide attempters attending the emergency.

\section{MATERIAL AND METHODS}

The study was a cross sectional, observational study conducted at the Community General Hospital Unit, Institute of Mental Health and NeurosciencesKashmir an associated hospital of Government Medical College Srinagar over a period of one and a half year from November 2017 to May 2019. This hospital is a specialized tertiary care psychiatric facility available in the valley - catering to the whole of Kashmir along with Ladakh and some parts of Jammu. Each patient was informed about the purpose of interview; his/her consent was obtained and strict confidentiality was ensured to the patient. Written informed consent was obtained.

The following inclusion and exclusion criteria were adapted.

\section{INCLUSION CRITERIA:}

1. Age $\geq 18$ years.

2. Those who gave consent.

\section{EXCLUSION CRITERIA:}

1. Those with Accidental injuries.

2. Suffering from severe neurological disorders

3. Those with severe medical illness

\section{INSTRUMENTS}

Modified Kuppuswamy Scale': Socioeconomic status was determined using the modified Kuppuswamy scale. This is an important tool in hospital and community based research in India, used to measure SES in urban and peri urban communities. It was devised by Kuppuswamy in 1976 in India and has been recently revised in 2017. ${ }^{63}$ It is based on composite score considering the education and occupation of the head of the family along with monthly income of family which yield a score of 329. This scale classifies study population into high, middle and low SES, which furher classified into five social classes: i) upper, ii) upper middle, iii) lower middle, iv) upper lower, v) lower socio-economic status.

MINI PLUS ${ }^{10}$ : For the diagnosis of psychiatric comorbidity, we used MINI International Neuropsychiatric Interview Schedule Plus (MINI PLUS).After the diagnoses of Psychiatric morbidity, diagnosis was discussed and confirmed by consultant psychiatrist. The MINI PLUS is DSM-IV based diagnostic interview with high reliability and validity. The MiniInternational Neuropsychiatric Interview (M.I.N.I. PLUS) is a short structured diagnostic interview, developed jointly by 
Shaveta Bhagat et.al. Psychiatric co-morbidities of suicide attempters: a cross sectional observation in a tertiary care hospital of North India.

psychiatrists and clinicians in the United States and Europe, for DSM-IV and ICD-10 psychiatric disorders. Psychometric examination of the MINI shows acceptable test-retest and inter-rater reliability. It was designed to meet the need for a short but accurate structured psychiatric interview for multicentre clinical trials and epidemiological studies. ${ }^{11}$ Interview was conducted after getting formal training in instituting MINI by trained psychiatrists of department of psychiatry GMC Srinagar.

\section{Statistical Analysis:}

The data collected was entered in a Microsoft excel spreadsheet. Continuous variables were summarized as mean and standard deviation and categorical variables were summarized as percentages. Fischer exact test was used to analyse the relationship between categorical variables. Psychiatric disorders were analysed using appropriate statistical tools. A p-value of $<0.05$ was taken as statistically significant.

\section{RESULTS}

A total of 221 cases who had been admitted following unsuccessful suicide attempts to the emergency and psychiatry department were taken up for the study. They were evaluated in detail with regards to socio-demographic profile and the presence of psychiatric morbidity and the results have been presented below in tabulated and graphical form (Table 1).

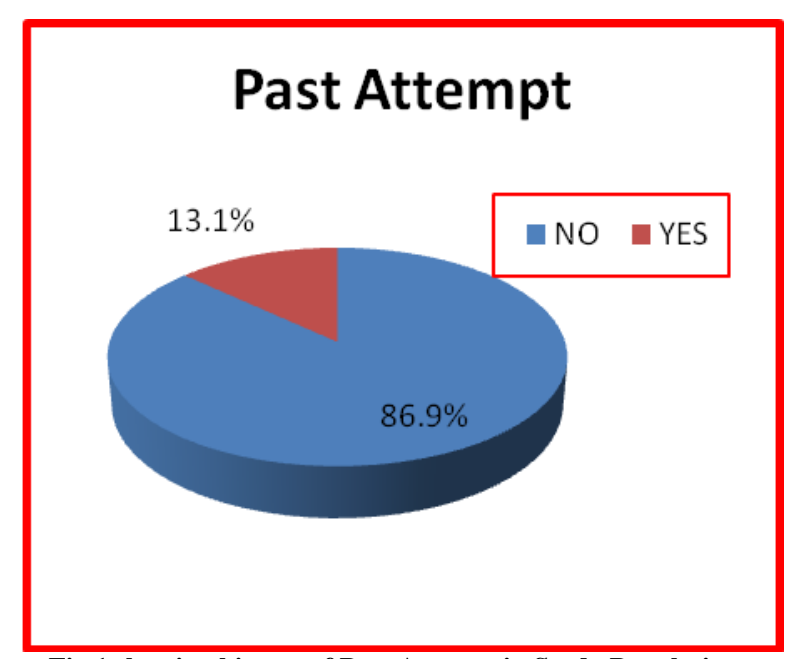

Fig 1 showing history of Past Attempt in Study Population
$13.1 \%$ patients had history of past suicidal attempt as shown in fig.1.

\begin{tabular}{|c|c|c|}
\hline Sex & Number & Percentage $(\%)$ \\
\hline Male & 60 & $27.1 \%$ \\
\hline Female & 161 & $72.9 \%$ \\
\hline \multicolumn{3}{|l|}{ Age (in Years) } \\
\hline $18-30$ & 188 & 85.1 \\
\hline $31-45$ & 25 & 11.3 \\
\hline $46-60$ & 8 & 3.6 \\
\hline \multicolumn{3}{|l|}{ Residence } \\
\hline Rural & 167 & 75.6 \\
\hline Urban & 54 & 24.4 \\
\hline \multicolumn{3}{|l|}{ Religion } \\
\hline Hindu & 1 & 0.5 \\
\hline Muslim & 220 & 99.5 \\
\hline \multicolumn{3}{|l|}{ Marital status } \\
\hline Unmarried & 144 & 65.2 \\
\hline Married & 67 & 30.3 \\
\hline Widowed & 0 & 0.0 \\
\hline Separated / divorced & 10 & 4.5 \\
\hline \multicolumn{3}{|l|}{ Family } \\
\hline Nuclear & 122 & 55.2 \\
\hline Extended & 15 & 6.8 \\
\hline Joint & 84 & 38.0 \\
\hline \multicolumn{3}{|l|}{ Occupation } \\
\hline Employed & 19 & 8.6 \\
\hline Unemployed & 123 & 55.7 \\
\hline Farmer & 15 & 6.8 \\
\hline Bussinessman & 16 & 7.2 \\
\hline Student & 48 & 21.7 \\
\hline \multicolumn{3}{|l|}{ Education } \\
\hline Illiterate & 33 & 14.9 \\
\hline Primary & 36 & 16.3 \\
\hline High School & 64 & 29.0 \\
\hline Hr. Sec. School & 48 & 21.7 \\
\hline Graduate / postgraduate & 38 & 17.2 \\
\hline Professional & 02 & 0.9 \\
\hline \multicolumn{3}{|l|}{ Socioeconomic status } \\
\hline Upper & 3 & 1.4 \\
\hline Upper middle & 53 & 24.0 \\
\hline Lower middle & 76 & 34.4 \\
\hline Upper lower & 76 & 34.4 \\
\hline Lower & 13 & 5.9 \\
\hline
\end{tabular}

$77.4 \%$ of the attempters had no history of psychiatric illness in their family while $22.6 \%$ of patients did have family history of a psychiatric illness (Table 2).

\begin{tabular}{|l|l|l|}
\hline \multicolumn{3}{|c|}{ Table 2. Family History of Psychiatric Illness } \\
\hline Family History of Psychiatry Illness & Frequency & Percent \\
\hline No & 171 & 77.4 \\
\hline Yes & 50 & 22.6 \\
\hline Total & 221 & 100.0 \\
\hline
\end{tabular}

$98.2 \%$ of attempters had no family history of suicide while $1.8 \%$ of the patients gave a family history of suicide (Table 3 ).

Table 3: Family History of Suicide

\begin{tabular}{|l|l|l|}
\hline \multicolumn{3}{|c|}{ Table 3: Family History of Suicide } \\
\hline Family history of suicide & Frequency & Percentage \% \\
\hline No & 217 & $98.2 \%$ \\
\hline Yes & 4 & $1.8 \%$ \\
\hline Total & 221 & $100 . \%$ \\
\hline
\end{tabular}


Shaveta Bhagat et.al. Psychiatric co-morbidities of suicide attempters: a cross sectional observation in a tertiary care hospital of North India.

\begin{tabular}{|l|l|l|}
\hline \multicolumn{3}{|c|}{ Table 4: Psychiatric Co-morbidities Among Males } \\
\hline Diagnosis & Frequency & Percentage \% \\
\hline MDD & 24 & 10.86 \\
\hline BPAD & 8 & 3.61 \\
\hline OCD & 3 & 1.36 \\
\hline PTSD & 1 & 0.45 \\
\hline Substance dependence & 3 & 1.36 \\
\hline Schizophrenia & 4 & 1.81 \\
\hline Borderline Personality disorder & 3 & 1.36 \\
\hline Psychotic depression & 1 & 0.45 \\
\hline Total & 47 & 21.26 \\
\hline
\end{tabular}

$21.26 \%$ males and $54.75 \%$ females had associated psychiatric co-morbidities and $23.9 \%$ had no associated psychiatric comorbidities (Table 4, 5). Comparison of psychiatric co-morbidities between males and females is shown in fig. 2 .

\begin{tabular}{|l|l|l|}
\hline \multicolumn{3}{|c|}{ Table 5: Psychiatric Co-morbidities among Females } \\
\hline Diagnosis & Frequency & Percentage \% \\
\hline MDD & 74 & 33.48 \\
\hline BPAD & 5 & 2.26 \\
\hline Agoraphobia & 1 & 0.45 \\
\hline OCD & 11 & 4.98 \\
\hline Psychotic depression & 1 & 0.45 \\
\hline Brief psychotic episode & 2 & 0.90 \\
\hline GAD & 1 & 0.45 \\
\hline Adjustment disorder & 7 & 3.16 \\
\hline Mixed anxiety depressive disorder & 8 & 3.62 \\
\hline Borderline personality disorder & 10 & 4.52 \\
\hline Histrionic personality disorder & 1 & 0.45 \\
\hline Total & 121 & 54.75 \\
\hline
\end{tabular}

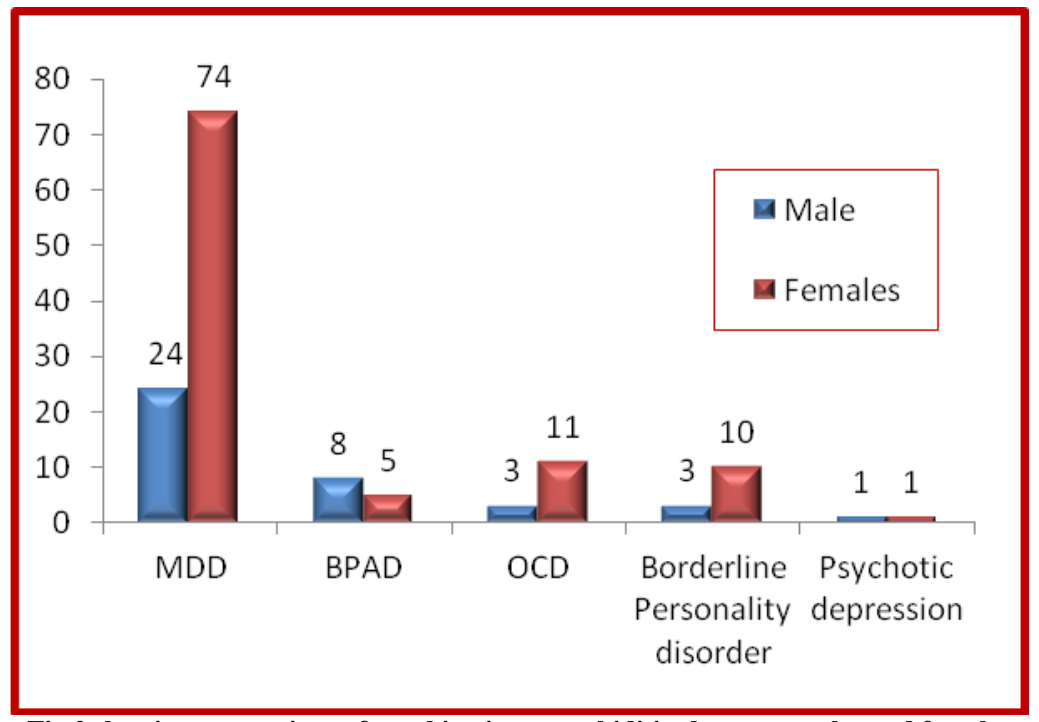

Fig 2 showing comparison of psychiatric co-morbidities between males and females

\section{DISCUSSION}

Kashmir is a conflict zone and has been constantly under stress for the past 20 years which has led to rise in mental illnesses in the valley as reported by many studies conducted by various researchers. $^{12,13,14}$ In recent times suicide rates are rising more quickly in adolescents and young people than any other age group, both in developing and developed countries and it has been seen that emotional issues, exam failures, peer pressure, substance abuse, financial difficulties, high parental expectations, family conflicts etc, are the triggering factors. ${ }^{15}$

In our study, the mean age was 24.61 years. This result is in concordance with the study conducted by Ghanate et $\mathrm{al}^{16}$ in 2013 in which majority of the patients (70\%) belonged to $15-30$ years of age group. Recent studies conducted by Manhas et $\mathrm{al}^{17}$, Shoib et.al ${ }^{13}$ (2012) and by Kodali et $\mathrm{al}^{18}$ showed similar results. Females outnumbered males as out of 221 cases, 161 were females $(72.9 \%)$ and $60(27.1 \%)$ were males. $29(13.1 \%)$ patients out of 221 had prior history of suicide attempts in which again female outnumbered males. Gould et al $(2003)^{19}$ reported that the adolescents often with past histories of suicide attempts are more vulnerable to suicide behaviour. Beghi $M$ et al $(2010)^{20}$ found previous attempts are the strongest risk factors for further attempt. In our study, only $4(1.8 \%)$ patients had positive family history of suicide attempt. A similar study conducted in Kashmir valley by shoib ${ }^{13}$ et al in 2012 also showed low percentage of family history of suicide among their study population. Further, only 50 patients $(1.8 \%)$ 
had history of psychiatric illness in their families.

$76 \%$ of patients in our study had underlying psychiatric co-morbidity at the time of suicide attempt, which confirms high association of psychiatric morbidity among suicide patients reported in the literature. $^{21}$ This result correlates with the study done in Kashmir valley by Jan, et $\mathrm{al}^{14}$ which showed $82 \%$ prevalence of psychiatric morbidity in their sample. Our finding is also in accordance with the study conducted by Qusar et $\mathrm{al}^{22}$, a study from outside the Kashmir valley, which observed that $59.1 \%$ patients attempting suicide were suffering from psychiatric disorders at the time of committing the act.

Major depressive disorder (MDD) (44\%) predominated amongst the psychiatric diagnosis in our study, which is in concordance with the study conducted by Shoib, ${ }^{13} \mathrm{Jan}^{14}$, and Das ${ }^{23}$. The diagnosis of MDD was more common among the females $(33.5 \%)$ than the males $(10.8 \%)$ in our study group and this difference was statistically significant $(\mathrm{p}=0.059)$.

Following MDD, the next common diagnosis was OCD (6.33\%), which was again more common in females. The figure was $2 \%$ in the study conducted by Jan et $\mathrm{al}^{14}$ in 2010.

The next diagnosis in the list was BPAD and Borderline Personality Disorder, with equal percentage $(5.9 \%)$. A similar study conducted in Kashmir in $2010^{14}$ showed $15 \%$ of cases had personality disorders in their study sample. Another study conducted by Roy et $\mathrm{al}^{24}$ in Bangladesh in 2018 had personality disorders in $7 \%$ of their study population which is close to the results in our study.

$3.6 \%$ cases in our study had mixed anxiety-depressive disorder, again more common in females.

$3.16 \%$ cases were suffering from adjustment disorder at the time of attempt, all of them were females. A study conducted by Das, et al showed $8.4 \%$ cases of adjustment disorders in their study, quite more than our study. ${ }^{23}$ Another study conducted by Shoib et $\mathrm{al}^{13}$ in 2012 showed adjustment disorder (9.95\%) next to depression.

Only 4 cases i.e $1.8 \%$ cases in our study had schizophrenia, all of them were diagnosed cases and were already on treatment. Shoib, et $\mathrm{al}^{13}$ had shown almost similar results in their study.

Other psychiatric diagnosis in our study includes psychotic depression $(0.9 \%)$, agoraphobia $(0.45 \%)$, PTSD $(0.45 \%)$, brief psychotic disorder $(0.45 \%) .24 \%$ of patients in our study did not meet any criteria under MINIPLUS and/or IPDE, and their acts were considered to be out of impulsivity. This figure is quite close to the results from the study conducted in Kashmir valley by Jan in $2010^{14}$ in which $18 \%$ of the cases did not meet any formal diagnostic criteria.

\section{CONCLUSION}

Almost $3 / 4^{\text {th }}$ of the cases had some kind of psychiatric morbidity. The most common psychiatric morbidity associated with suicide was found to be major depressive disorder. We need to have more of such studies from different centers across the state to characterize this population fully and also to look at the casual factors in a detailed way. There should be a robust system in place which takes care of future management and follow up of this group of population. There should be massive anti suicide campaigns and anti- suicide initiatives run on large scale across the state. People should be psycho-educated in general about mitigating such incidents which precipitate suicides.

Acknowledgement: None

Conflict of Interest: None

Source of Funding: None

Ethical Approval: Approved

\section{REFERENCES}

1. Sadock BJ, Sadock VA, Ruiz P. Kaplan and Sadock's synopsis of psychiatry 
behavioral sciences/ clinical psychiatry $11^{\text {th }}$ ed. 2015;763.

2. Brent DA, Baugher M, Bridge $\mathrm{J}$ et al. Age- and sex-related riskfactors for adolescent suicide.J Am Acad Child Adolesc Psychiat38: 1497-1505,1999

3. Gould MS, Fisher P, Parides M, Flory M, Shaffer D: Psychosocial risk factors of child and adolescent completed suicide.Arch Gen Psychiat53: 11551162, 1996.

4. Shaffer D, Gould M, Fisher P et al. Psychiatric diagnosis in child and adolescent suicide. Arch Gen Psychiat. 53:339-348, 1996b.

5. Lewinsohn PM, Rohde P, Seeley JR. Psychosocial risk factors for future adoles-cent suicide attempts.J Consult Clin Psychol62: 297-305, 1994.

6. Lecomte D, Fornes P. Suicide among youth and young adults, 15 through 24years of age: A report of 392 cases from Paris, 1989-1996.J Forensic Sci43:964-968, 1998.

7. Goldston DB, Daniel SS, Reboussin BA et al. Psychiatric diagnoses of previous suicide attempters, first-time attempters, and repeat attempters on an adolescent inpatient psychiatry unit.J Am Acad ChildAdolesc Psychiat37: 924-932, 1998.

8. Stein D, Apter A, Ratzoni $G$ et al. Association between mul-tiple suicide attempts and negative affect in adolescents.J Am Acad Child Ado-lesc Psychiat37: 488-494, 1998.

9. Singh T, Sharma S, Nagesh S. Socioeconomic status scales updated for 2017. Int J Res Med Sci 2017;5(7): 3264-3267.

10. Amorim P. Mini International Neuropsychiatric Interview (MINI): Validation of a short structured diagnostic psychiatric interview. Rev Bras Psiquitr 2000;22(3):106-115.

11. Sheehan DV, Lecrubier Y, Sheehan KH et al. The mini neuropsychiatric interview (MINI): the development and validation of structured and diagnostic psychiatric interview for DSM IV and
ICD-10. J Clin Psychiatry 1998; 59(20):22-33.

12. Margoob MA, Firdosi MM, Banal R et al. Community prevalence of trauma in South Asia-experience from Kashmir. JK-Practitioner 2006;13:S14-17.

13. Shoib S, Dar MM, Bashir $\mathrm{H}$ et al. Psychiatric Morbidity and the SocioDemographic Determinants of Patients Attempting Suicide in Kashmir Valley: A Cross-Sectional Study. IJHSR 2012;2(7):45-53.

14. Jan MM, Rather $\mathrm{YH}$, Majeed $\mathrm{N}$ et al. Psychosocial risk factors and clinical profile associated with attempted suicide in young adult and adolescent patients in conflict zone -Kashmir. Ann Trop Med Public Health 2017;10:154-159.

15. Baby S, Haridas MP ,Yesudas KF. Psychiatric diagnosis in attempted suicide. Calicut Medical Journal 2006;4(3):e2

16. Ghanate A, Deepak RS, Patil V et al. Sociodemographicprofile in suicide attempters.Int.J.Curr.Microbiol.App.Sci 2013; 2(3): 85-91.

17. ManhasR.S ,Manhas A, Manhas G. S.et al. Psychiatric morbidity among patients of suicide.JMSCR 2019; VOL 7 issue 6: 331-336.

18. Kodali M, Kilaru K. Psychiatric morbidity of attempted suicide patients admitted to a general hospital in rural area of south India. IOSR Journal of Dental and Medical Sciences 2013;4(3):46-50.

19. Gould MS. The Epidemiology of Youth. Suicide In: R.A; Apter, A. Suicide in children and adolescence. Cambridge: Camridge University Press, 2003,63-85.

20. Beghi M, Jerrold F, Rosenbaum. Risk factors for fatal and nonfatal repetition of suicide attempt: a critical appraisal: CurrOpin Psychiatry.2010;23(4):349355.

21. The Mental Healthcare Act, New Delhi: The Gazette of India.2017; 7(4).

22. Qusar MMAS. Psychiatric morbidity among suicide attempters who needed 
Shaveta Bhagat et.al. Psychiatric co-morbidities of suicide attempters: a cross sectional observation in a tertiary care hospital of North India.

ICU intervention. BSMMU J 2009;2(2): 73-77.

23. Das PP, Grover S, Avasthi A et al. Intentional self-harm seen in psychiatric referrals in a tertiary care hospital. Indian J psychiatry 2008; 50:187-91.

24. Roy J, Adiluzzaman A F, Hasan T et al. Socio-demographic profile and psychiatric morbidities of suicide attempters: a cross sectional observation in a tertiary care hospital of Bangladesh. Bang J Psychiatry. 2018; 30(2):36-40.

How to cite this article: Bhagat S, Dar MM, Ahmed I et.al. Psychiatric co-morbidities of suicide attempters: a cross sectional observation in a tertiary care hospital of North India. International Journal of Science \& Healthcare Research. 2021; 6(2): 40-46. DOI: https://doi.org/10.52403/ijshr. 20210408 